\title{
TWELVE WEEKS TREATMENT OUTCOME OF OMEGA-3 FATTY ACID IN COMPUTER VISION SYNDROME DRY EYE: AN OPEN LABEL, RANDOMIZED, CONTROLLED PILOT STUDY
}

\author{
Anita Thakur1, Ruchika Agarwal'2, A. M. Jain ${ }^{3}$, Nutan Saxena4, Chitra Rani Chauhan ${ }^{5}$ \\ ${ }_{1}^{1}$ Professor, Department of Ophthalmology, Rama Medical College, Hospital \& Research Centre, Mandhana, Kanpur. \\ ${ }^{2}$ Assistant Professor, Department of Ophthalmology, Rama Medical College, Hospital \& Research Centre, Mandhana, Kanpur. \\ 3Professor, Department of Ophthalmology, Rama Medical College, Hospital \& Research Centre, Mandhana, Kanpur. \\ ${ }^{4}$ Assistant Professor, Department of Ophthalmology, Rama Medical College, Hospital \& Research Centre, Mandhana, Kanpur. \\ ${ }^{5}$ Statistician Cum Assistant Professor, Department of Community Medicine, Rama Medical College, Hospital \& Research Centre, \\ Mandhana, Kanpur.
}

\section{ABSTRACT}

\section{BACKGROUND}

The incidence of Computer Vision Syndrome Dry Eye is on an increase. This study was targeted to evaluate the effect of Omega 3 Fatty Acids on this particular segment of population.

\section{METHODS}

A prospective, open label, randomized controlled trial was conducted on 67 male professional computer users aged 25-45 years who used computer for 8-10 hours a day. All the patients were subjected to OSDI questionnaire and patients with moderate-tosevere Dry Eye were included in the study. They were clinically monitored by TBUT, Rose Bengal Staining and Schirmer's 1 Test with anaesthesia on Day 1 and after 12 weeks of treatment. The patients were randomly divided into two groups. Group 1 (Prescribed only lubricant drops) consisted of 33 patients. Group 2 (Prescribed lubricant drops along with commercially available Omega 3 fatty acids with EPA $180 \mathrm{mg}$ and DHA $120 \mathrm{mg} 2$ capsules a day for twelve weeks) consisted of 34 patients.

\section{RESULTS}

Statistical Software SPSS 21.0 was used to analyse the results. In Group 1, the mean OSDI, TBUT, RBS, Schirmer's Test parameters before treatment were $32.425 .52,6.251 .32,3.72$ 2.47, 6.031 .40 and after treatment were 28.38 5.81, 7.06 2.03, 3.22 2.34, 6.531 .61 respectively. Whereas in Group 2 before treatment they were 33.09 5.89, 5.26 1.56, $4.242 .43,5.621 .58$ and after treatment were $14.766 .59,9.121 .47,0.881 .04,9.151 .65$ respectively.

\section{CONCLUSION}

The comparison of the scores of two Groups revealed an undeniably positive role of Omega 3 Fatty Acids in Dry Eye of Computer Vision Syndrome.

\section{KEYWORDS}

Dry Eye, Computer Vision Syndrome, Omega 3 Fatty Acids.

HOW TO CITE THIS ARTICLE: Thakur A, Agarwal R, Jain AM, et al. Twelve weeks treatment outcome of omega-3 fatty acid in computer vision syndrome dry eye: an open label, randomized, controlled pilot study. J. Evolution Med. Dent. Sci. 2016;5(48): 3070-3074, DOI: $10.14260 /$ jemds/2016/715

\section{INTRODUCTION}

The incidence of dry eye is as high as $90 \%$ in persons using computer for only 3 hrs. a day for a year. ${ }^{1,2}$ The magnitude of the problem is going to increase by leaps and bounds as our requirement for the use of computers has no limits. Dry eye has far reaching effects on our lifestyle.

A number of studies have made it abundantly clear, now that inflammation and disorder of immune system are the root causes responsible for reduction in tear secretion.3,4,5,6 It is not only the quantity of tear secretion, but also abnormalities of its quality that are responsible for the symptoms of dry eye.7,8 Thus, we need a strategy that should maintain the inflammatory and immune status of the ocular surface apart from maintaining the trilaminar lubrication barrier; its

Financial or Other, Competing Interest: None.

Submission 29-04-2016, Peer Review 24-05-2016,

Acceptance 30-05-2016, Published 15-06-2016.

Corresponding Author:

Dr. Anita Thakur,

\#501, Geetika Heights 7/106,

Swaroop Nagar,

Kanpur-208002.

E-mail: dranita_thakur@yahoo.com

DOI: $10.14260 /$ jemds/2016/715 volume, stability and chemical composition, i.e. maintain and repair the ocular surface round the clock without any untoward side effects.

Lubricants, our mainstay of treatment for Dry Eye with their short duration of action cannot prevent and halt the progress of the disease. Omega 3 fatty acids (PUFAPolyunsaturated Fatty Acids) with their anti-inflammatory, immuno-modulator and anti-apoptotic properties can be of great help in addressing this problem. ${ }^{9,10}$

Mechanism of action of EFA (Essential Fatty Acids) is better understood by their interactions (Figure 1).11,12,13 Short chain EFA-Omega6 (Linoleic Acid) and Omega 3 (Alpha linolenic acid) with the help of enzymes desaturase and elongase are converted to Long Chain Fatty Acids, AAArachidonic Acid, GLA-Gamma linolenic acid, DGLA-DihomoGLA, EPA-Eicosapentaenoic Acid, DHA- Docosahexaenoic Acid which are further converted to eicosanoids (PGProstaglandins, PGI-Prostacyclins, TX-Thromboxane by the enzyme Cyclooxygenase and LT-Leukotrienes by the enzyme15-Lypoxygenase). Eicosanoids of AA (PGE 2, LT-B4) result in pain and inflammation and act as messengers for the immune system to protect the body from further damage. Once the message is conveyed the messengers are turned off by 
eicosanoids from GLA, EPA and DHA (PGE 1, PGI 3 and LT-B5) that are less inflammatory, inert or anti-inflammatory. Less dietary intake of GLA, EPA and DHA leads to chronic inflammation. This inflammation can be ameliorated by stepping up the intake of these Fatty Acids, which interact with AA at 3 levels. ${ }^{14}$

1. Displacement-Increased dietary intake of omega 3 displace LA and thereby AA.

2. Competitive inhibition-EPA and DGLA compete for COX and LOX, thereby reducing the output of AA eicosanoids.

3. Counteraction - DGLA and EPA derived eicosanoids directly counteract their AA derived counterparts.

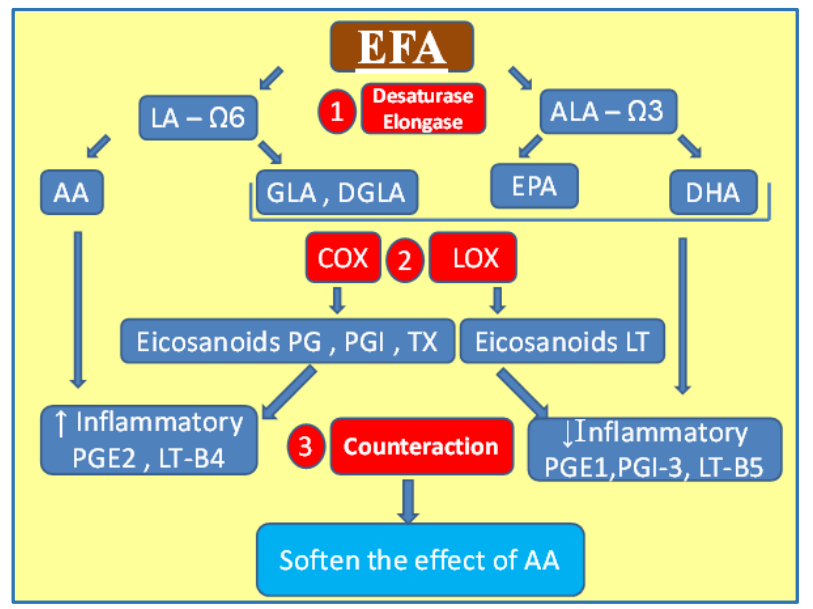

Fig. 1: Mechanism of Action

EFA-Essential Fatty Acids, LA-Linoleic Acid, ALA-Alpha Linolenic Acid, AA-Arachidonic Acid, GLA-Gamma Linolenic Acid, DGLA-Dihomo-GLA, EPA-Eicosapentaenoic Acid, DHADocosahexaenoic Acid, COX-Cyclooxygenase, LOXLypoxygenase, PG-Prostaglandins, PGI-Prostacyclins, TXThromboxane, LT-Leukotrienes.

Apart from Eicosanoid dependent mechanism, EFA also affects cellular signalling by making lipid rafts and altering gene expression by their effect on transcription factor and blockage of TNF $\alpha$ (Tumour Necrosis Factor), IL (Interleukin) and LT (Leukotriene), which is responsible for improved lacrimal secretion (Figure 2).15,16

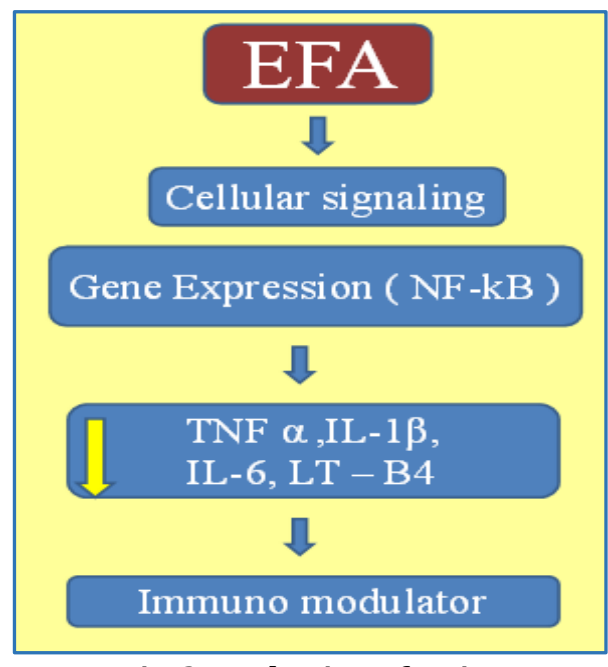

Fig. 2: Mechanism of Action

EFA-Essential Fatty Acids, NF-kB-Transcription Factor, TNF-Tumour Necrosis Factor, IL-Interleukin, LT-Leukotrienes
The Role of Omega 3 is Validated by a Number of Clinical Trials in,

- Reduction in ocular surface irritation symptoms.

- Halting the progression of inflammation.

- Maintenance of corneal surface smoothness.

Essential Fatty Acids are required to be consumed in the diet, as they are not synthesized in the body. We have evaluated the effect of supplementation of Omega 3 fatty acids in our study group.

\section{MATERIAL AND METHODS}

A prospective, open label, randomized, controlled trial was done on 67 professional computer users aged 25-45 years who used computer for 8-10 hours a day for a minimum of two years. Only male patients were enrolled so as to rule out hormonal and post-menopausal aetiology of Dry Eye. Patients above the age of 45 years, who may be having an element of age related reduction in tear secretion were excluded.

In this study patients with ocular, lid and lacrimal disease were not included. Those with systemic diseases and on drugs responsible for Dry Eye were also excluded. None of our patients were on antiplatelet, anticoagulant therapy or with bleeding disorders.

As Dry Eye is more of a symptomatic disease, all the patients were subjected to OSDI (Ocular Surface Disease Index) symptom severity questionnaire and patients with moderate-to-severe Dry Eye were included in the study.

Since it is not possible to rely solely on subjective response of the patients, who may have different pain thresholds, clinical tests were also added to correlate it with objective findings.

After thorough clinical examination, TBUT (Tear Break Up Time), Rose Bengal Staining and Schirmer's 1 Test with anaesthesia were studied.

The patients were randomly divided into two groups. Group 1 consisting of 33 patients were prescribed only lubricant drops. Group 2 consisting of 34 patients were prescribed commercially available Omega 3 fatty acids with EPA $180 \mathrm{mg}$ and DHA $120 \mathrm{mg}, 2$ capsules a day for twelve weeks along with lubricants.

At the baseline and final visits (After 12 weeks of treatment), patients filled OSDI questionnaire. The clinical signs and objective measurement parameters were evaluated and recorded. TBUT, Rose Bengal staining, Schirmer's 1 with anaesthesia was performed in that sequence. TBUT was performed (An average of three successive readings) and recorded. Schirmer's 1 Test with anaesthesia was measured at 5 minutes. Rose Bengal staining was done and graded as per Van Bijsterveld schema from 0-9.

\section{RESULTS}

A total of 67 men with computer vision syndrome were studied for the efficacy of Omega 3 Fatty Acids prescribed for 12 weeks. All the patients abided by the requirement of our study except for 1 from the control group who was lost for follow-up. Thus, Group 1 and Group 2 consisted of 32 and 34 patients respectively.

The mean age of the patients of the control group, i.e. Group 1 was 35.6 years and treatment group i.e. Group 2 was 35.8 years which was comparable. 
All the patients filled OSDI questionnaire before and after twelve weeks of treatment and objective parameters studied for efficacy of treatment were TBUT, Rose Bengal Staining and Schirmer 1 Test with anaesthesia.

The Statistical Analysis was performed using SPSS Software 21.0 version. Paired ' $t$ ' test was used to compare the pre- and post-treatment values, which are statistically significantly different in both the groups as shown in Table 1. We have also compared the change in the response parameters in the two groups. This has also been found to be statistically significantly different.

\begin{tabular}{|c|c|c|c|c|c|c|c|}
\hline $\begin{array}{c}\text { Para } \\
\text { Meters }\end{array}$ & Groups & $\mathbf{N}$ & $\begin{array}{c}\text { Pre- } \\
\text { Treatment }\end{array}$ & $\begin{array}{c}\text { Post- } \\
\text { Treatment }\end{array}$ & $\begin{array}{l}\text { Change } \\
\text { in Mean }\end{array}$ & $\begin{array}{c}\text { Paired } \\
t\end{array}$ & $\mathbf{p}$ \\
\hline \multirow{2}{*}{ OSDI } & 1 & 32 & $32.42 \pm 5.52$ & $28.38 \pm 5.81$ & 4.04 & 19.40 & \multirow{2}{*}{0.000} \\
\hline & 2 & 34 & $33.09 \pm 5.89$ & $14.76 \pm 6.59$ & 18.33 & 36.96 & \\
\hline \multirow{2}{*}{ TBUT } & 1 & 32 & $6.25 \pm 1.32$ & $7.06 \pm 2.03$ & 0.81 & 4.60 & \multirow{2}{*}{0.000} \\
\hline & 2 & 34 & $5.26 \pm 1.56$ & $9.12 \pm 1.47$ & 3.86 & 32.00 & \\
\hline \multirow{2}{*}{ RBS } & 1 & 32 & $3.72 \pm 2.47$ & $3.22 \pm 2.34$ & 0.5 & 5.57 & \multirow{2}{*}{0.000} \\
\hline & 2 & 34 & $4.24 \pm 2.43$ & $0.88 \pm 1.04$ & 3.36 & 10.82 & \\
\hline \multirow{2}{*}{ ST } & 1 & 32 & $6.03 \pm 1.40$ & $6.53 \pm 1.61$ & 0.5 & 4.98 & \multirow{2}{*}{0.000} \\
\hline & 2 & 34 & $5.62 \pm 1.58$ & $9.15 \pm 1.65$ & 3.53 & 23.89 & \\
\hline & & Tab & aster Table & ange of Val & Paramet & & \\
\hline
\end{tabular}

OSDI questionnaire revealed a change in the mean score of $18.33 \pm 2.89$ in Group 2 as compared to $4.04 \pm 1.18$ in Group 1 (Table $2)$, as reported by the patients. It is very highly statistically significant $(\mathrm{p}<0.001)$. This implies that treatment protocol in both the groups reduced the symptom severity, but the advantage gained in Group 2 is statistically significantly higher as compared to Group 1.

\begin{tabular}{|c|c|c|c|c|c|c|c|c|}
\hline \multirow{2}{*}{ OSDI } & \multirow{2}{*}{$\mathbf{N}$} & \multirow{2}{*}{$\begin{array}{c}\text { Change in } \\
\text { Mean }\end{array}$} & \multirow{2}{*}{ SD } & \multirow{2}{*}{$\begin{array}{c}\text { Mean } \\
\text { Difference }\end{array}$} & \multicolumn{2}{|c|}{$\begin{array}{l}\text { 95\% Confidence Interval } \\
\text { of the Difference }\end{array}$} & \multirow{2}{*}{$\mathbf{t}$} & \multirow{2}{*}{$\mathbf{p}$} \\
\hline & & & & & Lower & Upper & & \\
\hline Group 1 & 32 & 4.04 & 1.18 & \multirow{2}{*}{14.28} & \multirow{2}{*}{13.19} & \multirow{2}{*}{15.38} & \multirow{2}{*}{25.99} & \multirow{2}{*}{0.000} \\
\hline Group 2 & 34 & 18.32 & 2.89 & & & & & \\
\hline
\end{tabular}

Similar outcome was observed in analysis of objective parameters.

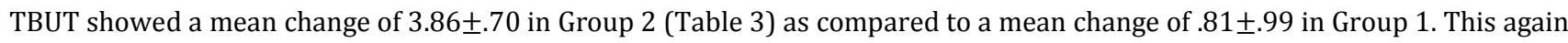
was statistically significant $(\mathrm{p}<0.001)$.

Mean change in RBS Score was $3.36 \pm 1.80$ in Group 2 (Table 4) and $.5 \pm 0.51$ in Group 1, which is also very highly significant in Group $2(\mathrm{p}<.001)$.

\begin{tabular}{|c|c|c|c|c|c|c|c|c|}
\hline \multirow[t]{2}{*}{ TBUT } & \multirow[t]{2}{*}{$\mathbf{N}$} & \multirow{2}{*}{$\begin{array}{l}\text { Change in } \\
\text { Mean }\end{array}$} & \multirow[t]{2}{*}{ SD } & \multirow[t]{2}{*}{ Mean Difference } & \multicolumn{2}{|c|}{$\begin{array}{c}\text { 95\% Confidence Interval of } \\
\text { the Difference }\end{array}$} & \multirow[t]{2}{*}{$\mathbf{t}$} & \multirow{2}{*}{$\mathbf{p}$} \\
\hline & & & & & Lower & Upper & & \\
\hline Group 1 & 32 & 0.81 & .99 & \multirow{2}{*}{3.04} & \multirow{2}{*}{2.62} & \multirow{2}{*}{3.46} & \multirow{2}{*}{14.38} & \multirow{2}{*}{0.000} \\
\hline Group 2 & 34 & 3.85 & .70 & & & & & \\
\hline
\end{tabular}

\begin{tabular}{|c|c|c|c|c|c|c|c|c|}
\hline \multirow[t]{2}{*}{ RBS } & \multirow[t]{2}{*}{$\mathbf{N}$} & \multirow{2}{*}{$\begin{array}{l}\text { Change in } \\
\text { Mean }\end{array}$} & \multirow[t]{2}{*}{ SD } & \multirow[t]{2}{*}{ Mean Difference } & \multicolumn{2}{|c|}{$\begin{array}{l}\text { 95\% Confidence Interval of the } \\
\text { Difference }\end{array}$} & \multirow[t]{2}{*}{$\mathbf{t}$} & \multirow{2}{*}{$\mathbf{p}$} \\
\hline & & & & & Lower & Upper & & \\
\hline Group 1 & 32 & 0.50 & 0.51 & \multirow{2}{*}{2.85} & \multirow{2}{*}{2.19} & \multirow{2}{*}{3.51} & \multirow{2}{*}{8.61} & \multirow{2}{*}{0.000} \\
\hline Group 2 & 34 & 3.35 & 1.80 & & & & & \\
\hline
\end{tabular}

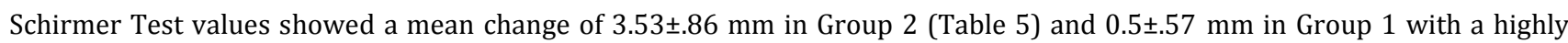
significant $\mathrm{p}$ value of $<0.001$.

\begin{tabular}{|c|c|c|c|c|c|c|c|c|}
\hline \multirow{2}{*}{ ST } & \multirow{2}{*}{$\mathbf{N}$} & \multirow{2}{*}{$\begin{array}{l}\text { Change in } \\
\text { Mean }\end{array}$} & \multirow{2}{*}{ SD } & \multirow{2}{*}{ Mean Difference } & \multicolumn{2}{|c|}{ 95\% Confidence Interval of the Difference } & \multirow{2}{*}{$\mathbf{t}$} & \multirow{2}{*}{$\mathbf{p}$} \\
\hline & & & & & Lower & Upper & & \\
\hline Group 1 & 32 & 0.50 & .57 & \multirow{2}{*}{3.03} & \multirow{2}{*}{2.67} & \multirow{2}{*}{3.39} & \multirow{2}{*}{16.76} & \multirow{2}{*}{0.000} \\
\hline Group 2 & 34 & 3.53 & .86 & & & & & \\
\hline
\end{tabular}




\section{DISCUSSION}

DEW Study has demonstrated how dry eye limits and degrades visual performance including the conduct of common visionrelated daily activities; apart from causing repetitive strain disorder and profound ocular morbidity. ${ }^{17}$ We have not yet found the optimum treatment options for different types and severity of the disease. A serious effort needs to be done to treat it at war footing.

Promising results are pouring in regarding the role of Omega-3 fatty acids in dry eye of different aetiologies. Although, it is not yet clear whether it works best on aqueous tear deficiency dry eye or lipid tear deficiency dry eye. However, it is amply clear that Omega 3 fatty acids have a softening role on inflammation of the ocular surface and immune-modulator properties, which may be responsible for improved tear production and its stability. EFAs are important constituents of cell membranes and influence the behaviour of membrane bound enzymes and receptors. Therefore, the membrane fatty acid composition can affect cell and organ functions. ${ }^{18}$

To consolidate this hypothesis, the role of Omega- 3 fatty acids in ever increasing aetiology of dry eye, i.e. Computer Vision Syndrome was studied.

Miller et al recommended an MCID (Minimum Clinically Important Difference) of 7.0 to 9.9 for all OSDI categories (4.5 to 7.3 for mild or moderate disease and from 7.3 to 13.4 for severe disease). A significant improvement in OSDI Scores in our study was found to be very encouraging. A mean difference of 18.33 in Group 2 in pre- and post-treatment scores was higher than MCID. This was statistically as well as clinically significant. It is also demonstrated by Kangari et $\mathrm{al}^{19}$ who found a difference of 9.4 in OSDI scores after 1-month treatment. A difference in the mean score in Group 1 was only 4.04 , which is even lesser than the lowest value of MCID. An improvement in subjective and objective parameters has also been reported by a number of researchers in different aetiologies of Dry Eye. ${ }^{20,21,22,23}$

This difference in subjective scores also reflected in objective tests.

TBUT showed a drift towards normal values with a mean of $9.12 \mathrm{sec}$. and a change in mean of $3.86 \mathrm{sec}$. Bhargava R. et $\mathrm{al}^{24}$ demonstrated a change in mean of $3.3 \mathrm{sec}$ after 3 months treatment (325EPA+125DHA), Kangari et al demonstrated a change in mean of $1.7 \mathrm{sec}$ after only a month's treatment. Although supplementation duration and its quantity varies in these studies, but there is a definite agreement about the beneficial effect of Omega 3 on this parameter. In Group 1, a change in mean was .81, which was hardly a deviation from baseline value as compared to Group 2 .

A significant change in Rose Bengal Staining indicates a healthier ocular surface. A change in mean of 3.36 was highly significant $(\mathrm{p}<.001)$. A statistically significant relation was also found by Bhargava et al.

A very significant change mean Schirmer values of 4.2 was found by Wojtowicz et al ${ }^{25}$ [Fish oil (EPA 450+DHA300) + flaxseed oil $1000 \mathrm{mg}$ for 3 months], whereas a very insignificant change in mean of .62 was found by Bhargava et al. Although, Schirmer test is an unreliable indicator of tear secretion, but in this study the mean change in Schirmer of $3.53(\mathrm{p}<.001)$ was commensurate with the changes in other indicators.
Literature has a number of studies regarding the role of Omega 3 Fatty Acids in Dry Eye. Studies available are done in different clinical conditions, study population and varying dose and duration, type of preparation and combinations of supplements. Similarly, different response parameters have been studied. It is difficult to draw a parallel between the outcomes of different studies. Yet they have one thing in common, that is the positive role of Omega 3 Fatty Acids in Dry Eye.

Although this is a pilot, single centre, open label study and has demonstrated a definite improvement in subjective as well as objective parameters with Lubricant drops only, but when Omega 3 Fatty Acids are added to the treatment the difference is significantly discernible. This implies that Omega 3 Fatty Acids have a definitive role in the treatment of Dry Eye of Computer Vision Syndrome.

\section{REFERENCES}

1. Rosenfield M. Computer vision syndrome: a review of ocular causes and potential treatments. Ophthalmic Physiol Opt 2011;31(5):502-15.

2. Bhargava R, Kumar P, Phogat $\mathrm{H}$, et al. Oral omega-3 fatty acids treatment in computer vision syndrome related dry eye. Contact Lens \& Anterior Eye 2015;38(3):206-10.

3. Stern ME, Bcuerman RW, Fox RI, et al. The pathology of dry eye: the interaction between the ocular surface and lacrimal glands. Cornea 1998;17(6):584-9.

4. Solomon A, Dursun D, Liu Z, et al. Pro-and antiinflammatory forms of interleukin-1 in the tear fluid and conjunctiva of patients with dry-eye disease. Invest Ophthalmol Vis Sci 2001;42(10):2283-92.

5. Behrens A, Doyle JJ, Stern L, et al. Dysfunctional tear syndrome study group. Dysfunctional tear syndrome: a Delphi approach to treatment recommendations. Cornea 2006;25(8):900-7.

6. Wilson SE. Inflammation: a unifying theory for the origin of dry eye syndrome. Manag Care 2003;12(12 suppl):149.

7. Sack RA, Conradi L, Krumholz D, et al. Membrane array characterization of 80 chemokines, cytokines, and growth factors in open-and closed-eye tears: angiogenin and other defense system constituents. Invest Ophthalmol Vis Sci 2005;46(4):1228-38.

8. Pflugfelder SC, Jones D, Ji Z, et al. Altered cytokine balance in the tear fluid and conjunctiva of patients with sjögren's syndrome keratoconjunctivitis sicca. Curr Eye Res 1999;19(3):201-11.

9. Simopoulos AP. Omega-3 fatty acids in inflammation and autoimmune diseases. J Am Coll Nutr 2002;21(6):495505.

10. Kew S, Mesa MD, Tricon S, et al. Effects of oils rich in eicosapentaenoic and docosahexaenoic acids on immune cell composition and function in healthy humans. The Am J Clin Nutr 2004;79(4):674-81.

11. Srinivasan S. Nutritional supplement stimulates tear production. Ophthalmology Times 2003;28(10).

12. Arterburn LM, Hall EB, Oken H. Distribution, interconversion, and dose response of $\mathrm{n}-3$ fatty acids in humans. Am J Clin Nutr 2006;83(6 Suppl):1467S-76S.

13. James MJ, Gibson RA, Cleland LG. Dietary polyunsaturated fatty acids and inflammatory mediator production. Am J Clin Nutr 2000;71(1 Suppl):343S-8S. 
14. Miljanovic B, Trivedi KA, Dana MR, et al. Relation between dietary n-3 and n- 6 fatty acids and clinically diagnosed dry eye syndrome in women. Am J Clin Nutr 2005;82(4):887-93.

15. Kang JX, Weylandt KH. Modulation of inflammatory cytokines by omega-3 fatty acids. Subcell Biochem 2008;49:133-43.

16. Zoukhri D, Kublin CL. Impaired neurotransmitter release from lacrimal and salivary gland nerves of a murine model of Sjogren's syndrome. Invest Ophthalmol Vis Sci 2001;42(5):925-32.

17. The epidemiology of dry eye disease: report of the epidemiology subcommittee of the international dry eye workshop (2007). Ocul Surf 2007;5(2):93-107.

18. Undurti ND. Essential fatty acids: biochemistry, physiology and pathology. Biotechnol J 2006;1(4): 420-39.

19. Kangari H, Eftekhari MH, Sara Sardari, et al. Short-term consumption of oral omega-3 and dry eye syndrome. Ophthalmology 2013;120(11):2191-6.
20. Miller KL, Walt JG, Mink DR, et al. Minimal clinically important difference for the ocular surface disease index. Arch Ophthalmol 2010;128(1):94-101.

21. Creuzot C, Passemard M, Viau S, et al. Improvement of dry eye symptoms with polyunsaturated fatty acids. J Fr Ophthalmol 2006;29(8):868-73.

22. Sheppard JD, Singh R, McClellan AJ, et al. Long-term supplementation with n-6 and n-3 PUFAs improves moderate-to-severe keratoconjunctivitis sicca: a randomized double-blind clinical trial. Cornea 2013;32(10):1297-304.

23. Macsai MS. The role of omega-3 dietary supplementation in blepharitis and meibomian gland dysfunction (An AOS Thesis). Trans Am Ophthalmol Soc 2008;106:336-56.

24. Bhargava $\mathrm{R}$, Kumar $\mathrm{P}$, Kumar $\mathrm{M}$, et al. A randomized controlled trial of omega- 3 fatty acids in dry eye syndrome. Int J Ophthalmol 2013;6(6):811-6.

25. Wojtowicz JC, Butovich I, Uchiyama E, et al. Pilot, prospective, randomized, double-masked, placebocontrolled clinical trial of an omega-3 supplement for dry eye. Cornea 2011;30(3):308-14. 